\title{
Determination of Trip Attraction Rates of Shopping Centers in Uttara Area, Dhaka
}

\author{
Md. Shamim Al Razib ${ }^{1}$, Faysal Ibna Rahman² \\ ${ }^{1}$ Department of Civil Engineering, Rajshahi University of Engineering \& Technology, Rajshahi, Bangladesh \\ ${ }^{2}$ Department of Civil and Environmental Engineering, University of Yamanashi, Kofu, Japan
}

Email address:

shamimrazib.ruet@gmail.com (Md. S. Al Razib), ovi_faysal@yahoo.com (F. I. Rahman)

\section{To cite this article:}

Md. Shamim Al Razib, Faysal Ibna Rahman. Determination of Trip Attraction Rates of Shopping Centers in Uttara Area, Dhaka. American Journal of Management Science and Engineering. Vol. 2, No. 5, 2017, pp. 150-155. doi: 10.11648/j.ajmse.20170205.19

Received: March 31, 2017; Accepted: April 19, 2017; Published: October 24, 2017

\begin{abstract}
Due to the high growth rate of urbanization in developing countries like Bangladesh leads to increase in vehicular traffic. Travel demand models are useful in managing the increased travel demand. So, Trip generation step is essential in planning of transportation facilities for Dhaka the capital of Bangladesh. In this study, the trip attraction rates of the shopping centers at Uttara Road, Uttara area of Dhaka are estimated by using trip rate analysis method. As part of this study, a total of six shopping centers are surveyed, for which the number of vehicles (car) and persons entering the shopping center during peak hour for every 15 minutes time interval are counted. The surveyed data deals with the relationship of trip attraction rates of the shopping center as a whole. Various physical features of the shopping centers are considered of this study, e.g total parking spaces, gross floor area, and the number of stores in the shopping center. This study will help for estimating the traffic volume of newly constructed shopping centers which has remarkable impact on the geometric design of roadways in the contiguous area.
\end{abstract}

Keywords: Trip Attraction Rate, Shopping Center, Urbanization, Transportation Planning, Uttara Road

\section{Introduction}

Rapid urbanization is now one of the major problems for developing countries. Due to the rapid growth of urbanization coupled with the increase in demand for transportation services makes the travel supply remained unmatched to travel demand. If the impact on a current road way increases people tends to take an alternate route to it far away from it. Road pattern and length changes accordingly to accessibility needs of people and desire to reach their dimension. These situations insisted more on managing travel demand rather than increasing infrastructure. [1-3]

Travel demand models are useful in this regard. The first step of travel demand forecasting is the trip generation which includes trip production and trip attraction. Trip attraction aims at predicting the total number of trips attracted to each zone of the study area and trip production identifies the number of trips produced by the households in the trip analysis zone. Trip attraction is important to the traffic engineer and urban planner in considering the impact of new development such as office complex, shopping center and residential development. One of the most important factors for trip attraction is work trips. Commercial or shopping trips are main category after work trips. This study creates the comparative relation with the trip attraction rate of the shopping centers and the number of people coming to the shopping center per unit time.

Though study of trip attraction is introduced very recent in Bangladesh but there are several studies have already done around the world. Uddin et al estimated the trip attraction rates of shopping centers at Dhanmondi Area in Dhaka City using trip rate analysis method instead of multiple regressions due to the small sample size. They related the trip attraction of the shopping center as a function of the physical features of the shopping center, e.g. total parking spaces, gross floor area, and the number of shops, employees in the shopping center [4].

Fillone and Tecson developed models using multiple regressions which showed that floor area was related to trip attraction. Thirty condominiums within Metro Manila were randomly selected and they conducted a questionnaire survey 
to collect the data related to the condominiums to know the characteristics of the selected condominiums and for modeling purpose. The data gathered include, available residential floor area, number of commercial establishments, parking slots, commercial floor area, occupancy rates, number of floors, years in operation, maintenance fee [5].

Baumeler et al, in their conference paper aim to identify crucial spatial characteristics of neighbourhoods and of shopping destinations, which has an impact on the distance, destination and modal split of shopping trips. They were taken the data for this study from the Swiss national travel survey, which contains individual information on the socioeconomic status and the travel behaviour of approximately 30,000 people. The important independent variables they selected for their study includes the number of different stores like, supermarket, consumer market, small and large stores, sum of stores in the neighbourhood [6].

The first zonal based trip generation analysis is done in the Chicago area [7]. In the later analysis, the approach developed at CATS (Chicago Area Transportation Study) was considerably modified. Earlier, many researchers are explored these trip generation studies and developed various models for estimating trip generation rates. Most of these studies related to residential land use. Commercial centers are one of the major trip attraction areas in any part of the world. Some of the researchers have made an attempt to estimate the trip attraction rates of various commercial centers [8-11].

Waloejo et al determined the characteristics of trip attraction at the market land use and its influencing factors and he also formulated a model of trip attraction and a model of trip delay analysis at Dinoyo market area. For model formulation correlation and regression analysis are used. Other supporting analyses are ANOVA, parking systems, road capacity and analysis of the level of services [12].

Innes et al conducted a study to determine the major factors affecting shopper's destination choice. They included the factors, store hours of operation, quality of goods offered, availability of parking, price of goods, accessibility to the shopping area, selection of goods offered and protection from environmental influences for the modeling [13].

The purpose of this study is to collect data about the number of people coming to shopping centers at Uttara Area in Dhaka City and also study the trip attraction rate variation for different shopping centers in the same area. This study also provides the foundation for subsequent research to be conducted, local agencies, and/or private organizations to further build a comprehensive urban trip attraction database of shopping centers. The obtained database will be utilized for planning and design of shopping centers for the geometric design as well as for traffic control schemes on the roadways around the shopping centers and thereby, proper planning of transportation facilities and services can be effectively done by the urban planners and traffic engineers.

\section{Methodology}

\subsection{Data Collection}

In this study trip rate analysis method is used because it is comparatively suitable method than regression model for analyzing the Trip Attraction Rates for small sample size. To accomplish the purpose, six shopping centers around Uttara area are surveyed. The shopping centers are North tower, Mascot plaza, Rajuk commercial complex, London plaza, Baly complex and Rajlaxmi complex. The location of six shopping centers is marked by yellow star symbol in Figure 1. There are few behaviors were counted such as for shopping, fitness centers and other services for the people and vehicles attracted to the shopping centers when they visit the particular building. The data is collected by surveyors from the entrance and exit of the shopping centers while also they investigate on-street parking lots around the malls to insure whether the tenants of the vehicles parked on the road are going to the building or not.

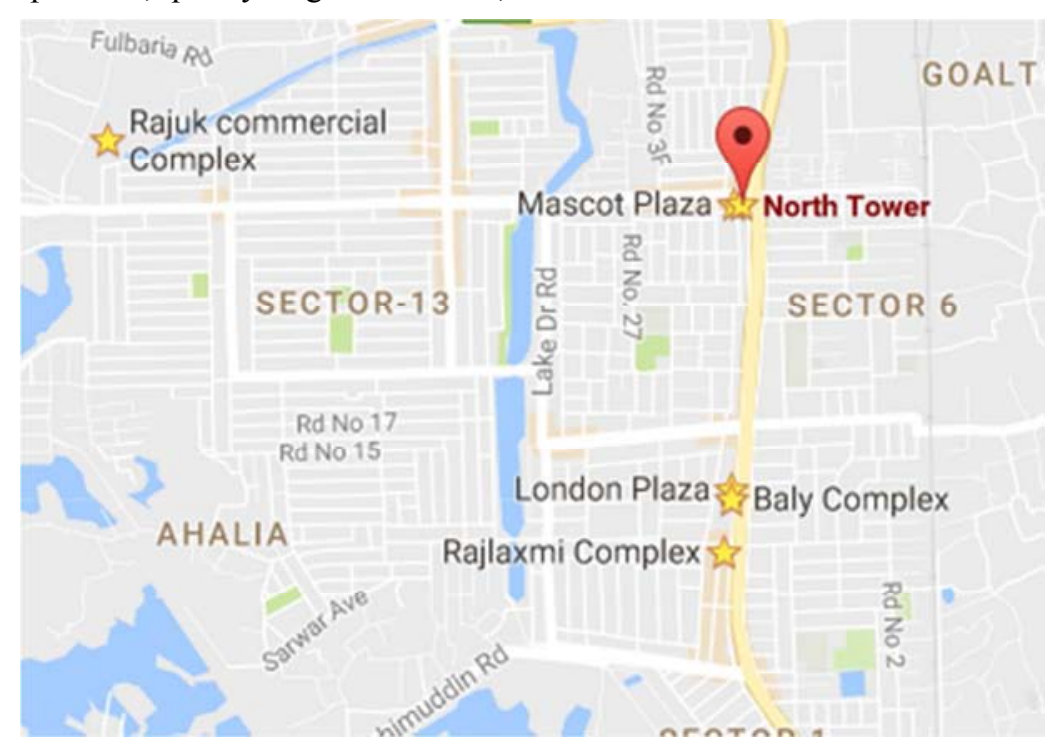

Figure 1. Surveyed Shopping Centers in Uttara Area (Source: Google Map). 
The data is collected in the form of manual counting procedure. One surveyor is appointed in each gate of the shopping center and data is counted in every 15 minutes. To understand the daily variation between the trip attraction rates, two days data are collected, one is on weekend (Friday) and other one is on weekday (Saturday) for a span of three peak hours (4.30-7.30) pm. For each shopping center, data are collected for two days to get the shopper trip variation during week day and weekend. There is a large variation in the number of people coming to the shopping center depending on the number of the time of the day, day of the week and the season. The fluctuations in the Trip Attraction Rate of the stores and the shopping center on the whole show the complexity involved in studying the trip attraction of shopping centers. The two different day data of the number of vehicles and people shows the specific characteristics of each individual shopping center and from that data statistical analysis is used to determine trip attraction rate. This study reveals the recent trip attraction pattern of the newly developed area of Dhaka City. The whole study plan is shown in Figure 2.

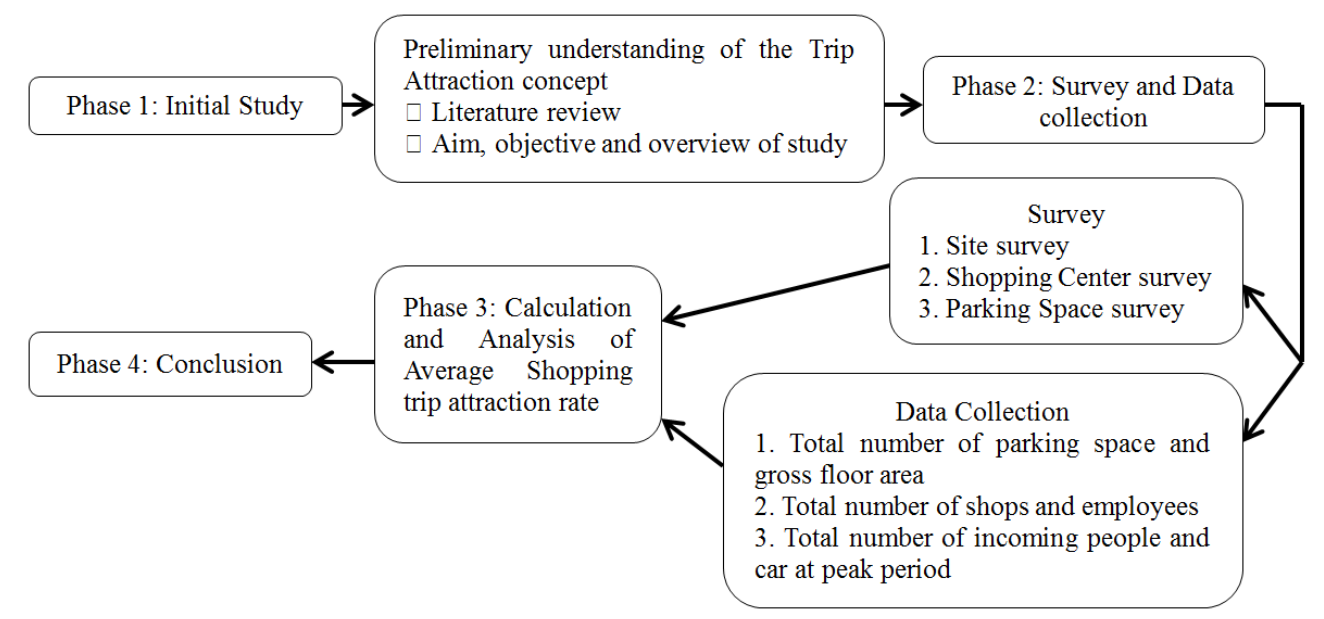

Figure 2. Flow chart of the study.

\subsection{Data Analysis}

Uttara area is one of the developing area of Dhaka city. A few years ago some research had been done on trip attraction rate at Dhanmondi and Mirpur area in Dhaka city but there is no research has done in Uttara area on trip attraction. Besides, we choose six shopping centers e.g. North tower,
Mascot plaza, Rajuk commercial complex, London plaza, Baly complex and Rajlaxmi complex among twenty shopping centers in that area because these shopping centers are the busiest and reputed shopping centers where most of the people come for shopping. Some important information about those shopping malls is given below.

Table 1. Details information about six shopping centers in Uttara area.

\begin{tabular}{|c|c|c|c|c|c|c|c|}
\hline $\begin{array}{l}\text { Name of the Shopping } \\
\text { center }\end{array}$ & $\begin{array}{l}\text { Floor area } \\
\text { (sq. ft) }\end{array}$ & $\begin{array}{l}\text { Parking } \\
\text { space }\end{array}$ & $\begin{array}{l}\text { No of shop } \\
\text { (per floor) }\end{array}$ & $\begin{array}{l}\text { No of floor } \\
\text { (used) }\end{array}$ & $\begin{array}{l}\text { No of entry } \\
\text { gate }\end{array}$ & $\begin{array}{l}\text { Total no of employee } \\
\text { (per shop) }\end{array}$ & $\begin{array}{l}\text { Restaurant } \\
(\text { yes }=1, \text { no }=0)\end{array}$ \\
\hline North tower & 14400 & Yes & 30 & 7 & 2 & 4 & 1 \\
\hline Mascot plaza & 14400 & Yes & 26 & 6 & 2 & 2 & 0 \\
\hline Rajuk co. complex & 18300 & Yes & 33 & 6 & 2 & 3 & 1 \\
\hline London plaza & 18000 & Yes & 28 & 3 & 1 & 2 & 0 \\
\hline Baly complex & 17800 & Yes & 27 & 3 & 2 & 2 & 0 \\
\hline Rajlaxmi complex & 18500 & Yes & 45 & 6 & 3 & 4 & 0 \\
\hline
\end{tabular}

The following equations are used for calculating different trip attraction rate:

1. Peak hour person trip attraction rate (Trips per 1000 sq. ft. per hour $)=($ Peak hour person trip /Gross Floor Area $(\mathrm{GFA}))^{*} 1000$

2. Peak hour person trip attraction rate (Trips per shop per hour $)=($ Peak hour person trip/total number of shop $)$

3. Peak hour person trip attraction rate (Trips per entry gate per hour $)=($ Peak hour person trip/number of entry gate $)$

4. Peak hour person trip attraction rate (Trips per 100 employees per hour $)=($ Peak hour person trip/total no of employee of shopping center)*100
5. Peak hour car trip attraction rate (Trips per 10 parking spaces per hour $)=($ Peak hour car trip/total number of parking spaces)*10

6. Peak hour car trip attraction rate (Trips per 10,000 sq. ft. per hour $)=(\text { Peak hour car trip/ Gross Floor Area })^{*} 10,000$

Using the equations above Trip Attraction Rates was calculated for six shopping centers and also for week day and weekend. Then standard deviation of Average Trip Attraction Rate of the shopping centers from Grand Average was calculated using the equation below.

$$
\sigma=\sqrt{\frac{1}{N} \sum_{i=1}^{N}\left(x_{i}-\mu\right)^{2}}, \text { Where, } \mu=\frac{1}{N} \sum_{i=1}^{N} x_{i} ; \text { (Note: } \sigma=
$$


Standard Deviation, $\mathrm{N}=$ Number of Shopping Centers, $\mathrm{x}_{\mathrm{i}}=$ Trip Attraction Rate for different Malls, $\mu=$ Average Trip Attraction Rate)

\section{Results}

From the experimental study, it was observed that most of the shopping centers are having its peak business hours in between $4.30 \mathrm{pm}$ to $7.30 \mathrm{pm}$. Hence, in this study, data is collected between $4.30 \mathrm{pm}$ to $7.30 \mathrm{pm}$. The collected data of people and vehicles is analyzed for every 15 minutes interval. The highest hourly data is taken as peak hour trip rates for each shopping center. This process is followed for both weekday and weekend analysis. From the results, it shows the average trip rates attracted by the each shopping center in weekday and weekends respectively and it is also clearly depicted that all the shopping centers are attracting more number of trips in weekends.

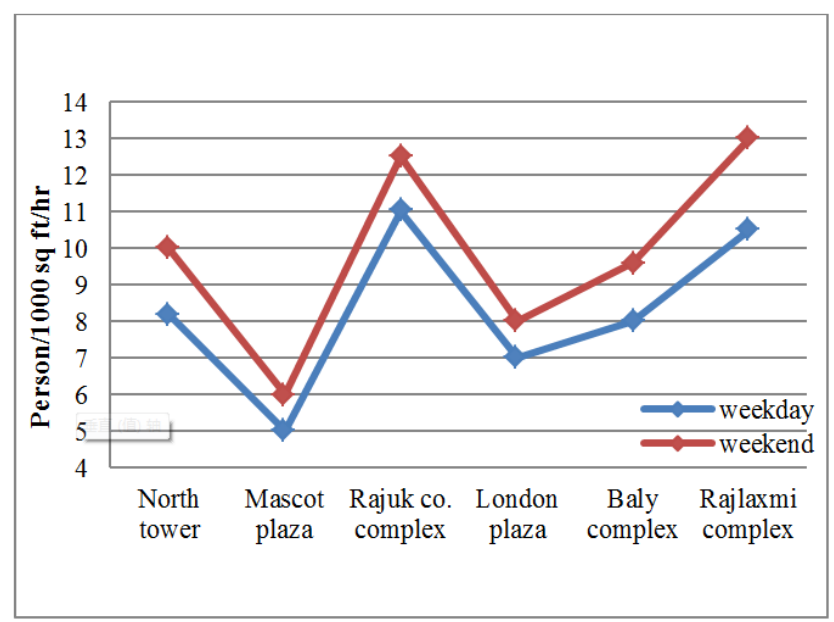

Figure 3. Pick hour Person Trip Attraction Rate (Person/1000 sq. ft/hr) variation for Different shopping centers.

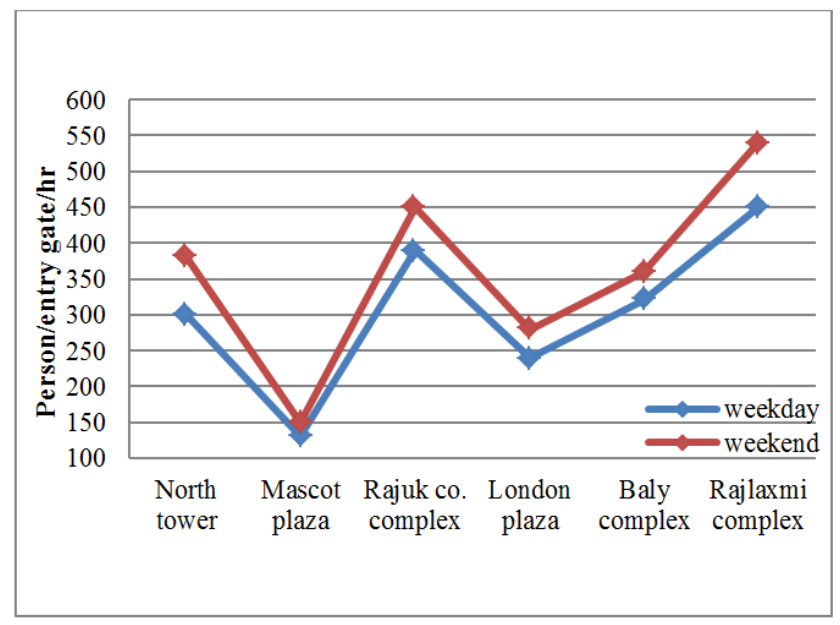

Figure 4. Pick hour Person Trip Attraction Rate (Person/entry gate/hr) variation for different shopping centers.

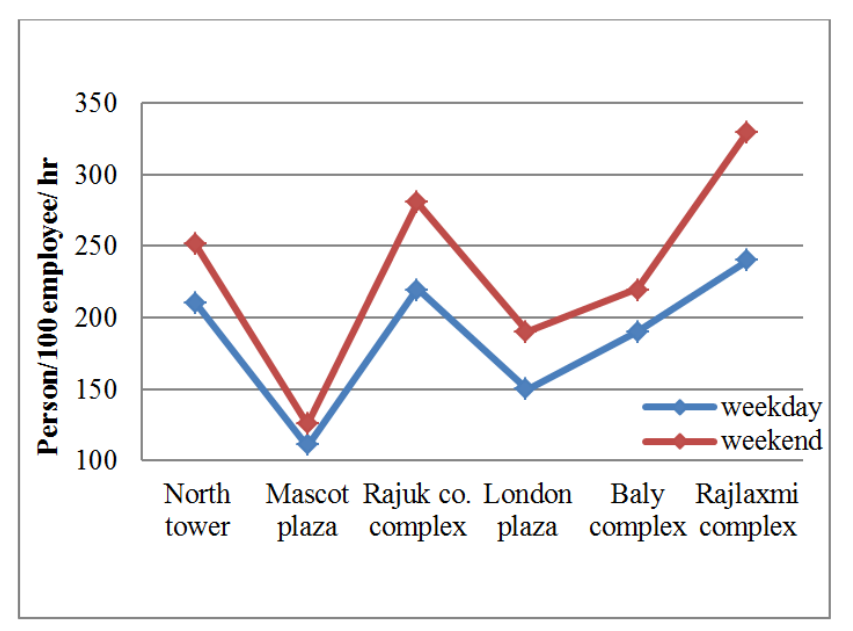

Figure 5. Pick hour Person Trip Attraction Rate (Person/100 employee/hr) variation for different shopping centers

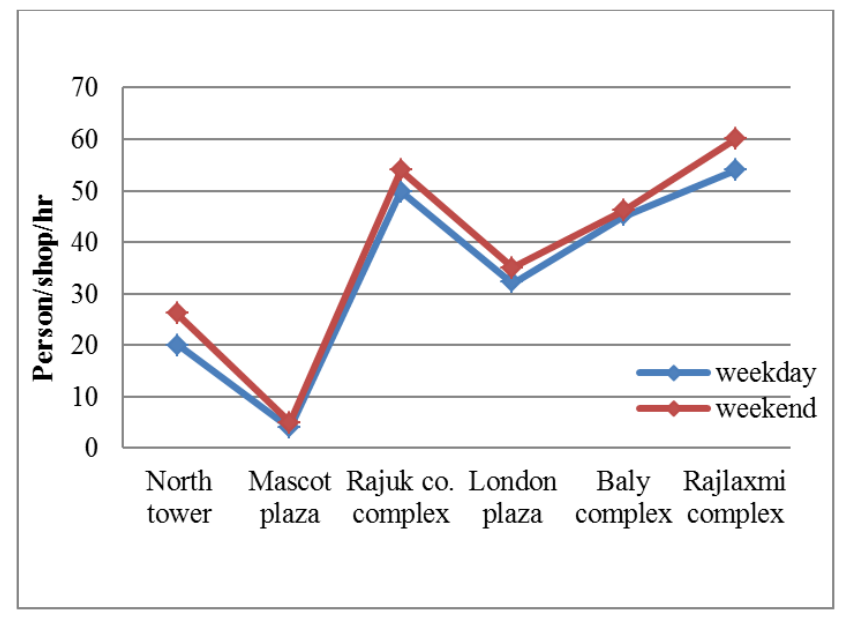

Figure 6. Pick hour person Trip Attraction Rate (Person/shop/hr) variation for different shopping centers.

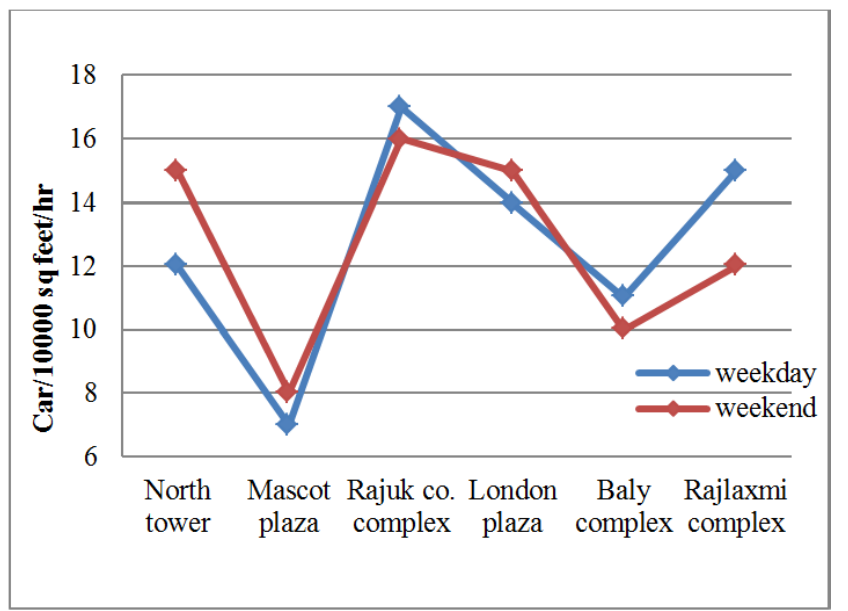

Figure 7. Pick hour Car Trip Attraction Rate (Car/10000 sq. ft/hr) variation for different shopping centers. 


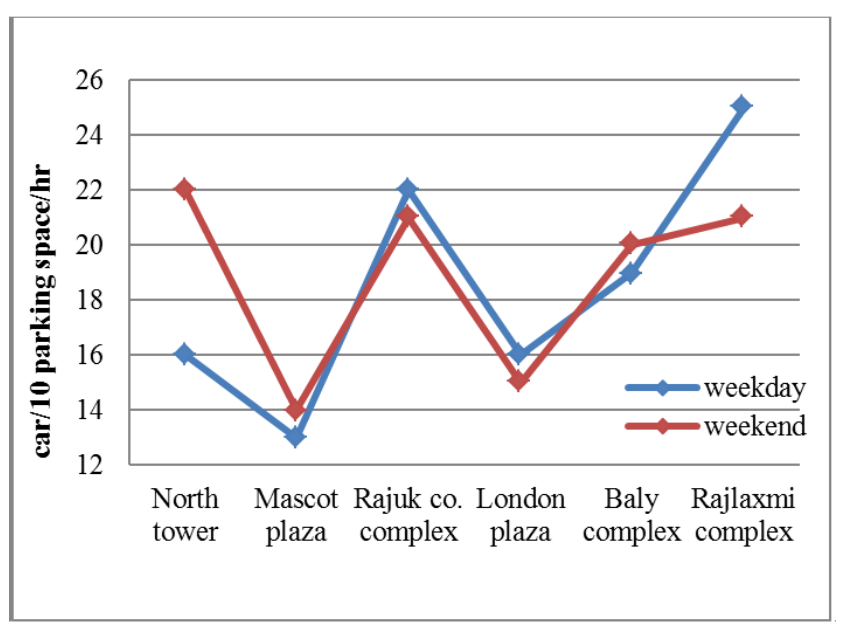

Figure 8. Pick hour Car Trip Attraction Rate (Car/10 parking space/hr) variation for different shopping centers.

\section{Discussions}

From Figure 3, highest peak hour person Trip Attraction Rate is in Rajlaxmi Complex with 13 person trip/1000 sq. $\mathrm{ft} /$ hour on weekend. Rajlaxmi Complex attracted highest person trips per 1000 sq. $\mathrm{ft}$ area during peak hour because it is a popular shopping mall of branded clothing. Mascot Plaza has lowest peak hour Trip Attraction Rate 5 person trip/1000 sq. ft/hour on weekday and 6 person trip/1000 sq. ft/hour on weekend and the rest all have the value of around 8.5 person trip/1000 sq. ft/hr. From the graph, it is clearly noticeable that weekends are found with higher Trip Attraction Rate (person trip/1000 sq. ft/hour) than weekday (typical working day) for six shopping centers because on weekend the shopping centers attract more shoppers. Figure 4 represents the variation in peak hour Person Trip Attraction Rate (person/entry gate/hour) of six shopping centers and again Rajlaxmi Complex is found with highest person trip/entry gate/hour with a value of 540 on weekend. Mascot Plaza has made lowest Trip Attraction Rate with a value of 150 person/entry gate/hour on weekend. And the others such as North tower, Rajuk commercial complex, London plaza and Baly complex have 380, 450, 280 and 360 (person/entry gate/hour) respectively. A weekend trip attraction rate for the shopping exceeds the weekday shopping centers in all cases. It is natural that at weekend shoppers have more free time to spend in the shopping centers than the week days.

Figure 5 limns the peak hour Trip Attraction Rate (Person/100 employee/ hr) variation of six shopping centers. Mascot Plaza is found with least peak hour Trip Attraction Rate value 110 (Person/100 employee/ hr) on weekday. Rajlaxmi Complex has highest Trip Attraction Rate 330 (Person/100 employee/ hr) on weekend and the others have the value of nearly 200 (Person/100 employee/ hr). Figure 6 expounds the peak hour Trip Attraction Rate (Person/shop/hr) variation of six Shopping Centers. Rajlaxmi Complex once again has made highest Trip Attraction Rate 60 (Person/shop/hr) on weekend whereas, 54 (person/shop/hour) on weekday. Mascot Plaza produces least peak hour Trip
Attraction Rate value 4 (Person/shop/hr).

The variation in peak hour Car Trip Attraction Rate (trips $/ 10,000$ sq. ft/hour) of six shopping centers is showed in Figure 7. Rajuk commercial complex has the highest Car Trip Attraction Rate 17 trips/10,000 sq. ft/hour on weekday. Again Mascot Plaza has made lowest (trips/10,000 sq. ft/hour) with a value of 7 on weekday and 8 on weekend. Car trip attraction is lowest here because it is situated near residential area and most of its regular customers can easily come here by walking. In majority, except Rajuk commercial complex and Mascot Plaza, it is interesting to note that car trip attraction rate on weekday is greater than the weekends as people love shopping on holidays with their family. Figure 8 explains variation of peak hour car trip attraction rate among different shopping malls. The highest trip attraction rate (car trip/10 parking spaces/hour) is produced by Rajlaxmi Complex weekday and the value is 25 (car trip/10 parking spaces/hour). For weekend the highest value is 22 (car trip/10 parking spaces/hour) by North Tower. This is because shoppers prefer car trip to shopping center more in weekday than weekend to avoid traffic congestion near shopping centers. In case of the remaining shopping centers the car trip attraction rate on weekday is greater than weekend for both Rajuk commercial complex and London plaza except Baly complex. The car trip attraction rate is lowest for Mascot Plaza Shopping Centers. The value is 13 (car trips/10 parking spaces/hour) for weekday.

Grand Average of peak hour person trip attraction rate is found 9.04 person trips/1000 sq. $\mathrm{ft} /$ hour for all six shopping centers. The range of values are between 5 to 13 trips /1000 sq. $\mathrm{ft} /$ hour for different shopping centers and with a standard deviation (S.D.) of 2.37 (trips/1000 sq. ft/hour). Again, Grand Average of peak hour person Trip Attraction Rate is estimated 332.5 trips/entry gate/hour. Minimum value is 130 trips/entry gate/hour and maximum is 540 trips/entry gate/ hour for different shopping centers and with a standard deviation (S.D.) of 116.84 trips/entry gate/hour. On the other hand, Grand Average of peak hour person trip attraction rate is found 209.58 trips/100 employee/hour. It is observed that the range is between 110 to 330 trips/100 employee/hour with a standard deviation (S.D.) of 60.3 (trips $/ 100$ employee/hour).

From the analysis, grand Average of peak hour car trip attraction rate is found 14.25 car trips $/ 10,000 \mathrm{sq}$. $\mathrm{ft} / \mathrm{hour}$. Range of values has started from 7 car trips/10,000 sq. $\mathrm{ft} /$ hour to 17 car trips/10,000 sq. ft/hour) for different shopping centers and with a standard deviation (S.D.) of 3.45 car trips/ 10,000 sq. $\mathrm{ft} /$ hour. Again, the average of peak hour car trip attraction rate is found 18.67 car trips $/ 10$ parking spaces/hour. Minimum value is 13 car trips/10 parking spaces/hour where maximum value is calculated as 25 car trips/parking spaces/hour for different shopping centers and with a standard deviation (S.D.) of 3.61 car trips/10 parking spaces/hour. Grand Average of peak hour person Trip Attraction Rate is found 35.92 trips/shop/hour. Minimum value is 4 trips/shop/hour whereas, maximum is 60 trips/shop/hour for different shopping centers and with a 
standard deviation (S.D.) of 18.16 trips/shop/hour.

In briefly from those six figures we can say that, the trip attraction rate for both person and car is fluctuated from one shopping center to another in the whole time. In case of person trip attraction rate Rajlaxmi complex has always the leading position but Mascot plaza has the lowest position and the rest of all have average position in different cases e.g. per $1000 \mathrm{sq}$. ft, per entry gate etc. and there is a considerable deviation in this case. Now in case of car trip attraction rate Rajuk commercial complex has some great value most of the time but Mascot plaza has the lowest as usual and the other shopping centers has nearly to the average value and the standard deviation in this case is almost negligible.

From this whole data analysis, we can ensure the maximum and minimum number of person and cars enter in the shopping centers during the pick hour (4.30-7.30) pm. By using these data we can calculate traffic volume of adjacent roads of the shopping centers which can be used for designing road and control of traffic of surrounding area of the shopping centers. These data can also be utilized for building new shopping centers in the same region because they can estimate number of entry gate, car sparking space etc. by taking idea from data of the adjacent shopping malls.

\section{Conclusions}

This study explores the trip attraction rates of shopping centers at Uttara areas in Dhaka. Because of shopping malls great share in economy of that area, these trips not only influence the individual travel behavior but also showing great impact on transport network. In this area, a total of six shopping centers are surveyed and the trip attraction rate is calculated by considering various physical features of the shopping centers.

Trip Attraction Rate at Uttara area is fundamental in planning of transportation facilities and very useful for regional transportation network or the channelization of traffic control around a shopping center. Because by knowing the trip rate of a region we can estimate the no of people and car entering that area in a specific time which is definitely very useful for designing and controlling the traffic in that region. The data and the model should be useful in assessing the traffic impacts surrounding a new shopping center, and also the region wide traffic volume impacts.

The main demerits of this study are the limited number of studied shopping centers and factors considering for the study. It only considers the physical features as a function of trip attraction rate of the shopping centers. It will create complication if two shopping centers with different composition of stores exists similarities in physical features. For further research, more independent Trip Attraction variables of activity centers like distance from home to Trip Attraction center, duration of average long and short trip to destination, variety and prize of products available in shopping centers, different time in several day in a week, average annual daily traffic and traffic congestion situation near the shopping malls etc. may be included.
The trip attraction rate data of this study area can be used as a database to develop new shopping centers in Dhaka city as well as the whole country. And as it is new in Bangladesh, it will be very useful for future researcher and might helpful in accurate prediction of trip rates and also planning of transportation facilities in Uttara area.

\section{References}

[1] Shoup, D. C., "The Trouble with Minimum Parking Requirements," Transportation Research, 1999, Part A, Vol. 33, pp. 549-574.

[2] International Association of Traffic and Safety Sciences (2001) "Traffic Assessment Study," Tokyo. (Original version in Japanese translated into English).

[3] Yam Richard C. M., Whitfield, R. C. and Chung, R. W. F., "Forecasting Traffic Generation," Journal of Transportation Engineering, 2000, pp. 358-361.

[4] M. M. Uddin, M. R. Hasan, I. Ahmed, P. Das, M. A. Uddin, and T. Hasan, "A Comprehensive Study on Trip Attraction Rates of Shopping Centers in Dhanmondi Area," International Journal of Civil \& Environmental Engineering, IJCEE-IJENS Vol.12 No. 4.

[5] A. M. Fillone and M. R. Tecson, "Trip Attraction of MixedUse Development in Metropolitan Manila," Proc., Eastern Asia Society for Transp. Studies, Vol.4, 2003 October, pp. 860- 868 .

[6] M. Baumeler, A. Simma, and R. Schlich, "Impact of Spatial Variables on Shopping Trips," STRC fifth Swiss Transport Research Conference, 2005 March, pp. 9-11.

[7] Hutchinson G., "Principles of urban transport system planning book". Trip distribution models. MacGraw-Hill Book, 1974.

[8] Goulias K. G., Pendyala R. M., Kitamura R., "Practical method for the estimation of trip generation and trip chaining," Transportation Research, 1991 Mar.

[9] Navya S. V., Kumar S. S., Kattoor G. J., "Trip generation model for the core area of Thiruvananthapuram city," International Journal of Innovative Research in Science Engineering and Technology, 2013 Dec., Vol. 2, No.1, pp. 18.

[10] Prakash S, Radhakrishnan N., "Trip generation analysis in the Devasthanam ward of Tiruchirapalli city," Tamil Nadu. International Journal for Scientific Research and Development, 2014 Mar, Vol. 2, No.1, pp. 5-10.

[11] Zenina N, Borisov A., "Regression analysis for transport trip generation evaluation. Information Technology and Management Science, 2013, pp. 1-6.

[12] B. S. Waloejo, Surjono, and H. Sulistio, "The Influence of Trip Attraction on the Road's Level of Service (LOS) at Traditional Market Land Use," J. Applied Envir. And Biological Sci., 2012 February, pp. 92-96.

[13] J. D. Innes, M. C. Ircha, and D. A. Badoe, "Factors affecting automobile shopping trip destinations," J. Urb. Plan. And Development, 1990 Dec., Vol. 116, No. 3. 